\title{
La marca de uso metafórico para el náhuatl: una innovación de la lexicografía hispano-amerindia
}

\section{Esther Hernández}

Instituto de Lengua, Literatura y Antropología, CCHS-CSIC

\section{Introducción}

Fray Alonso de Molina ( $\dagger 1580)$ en su Vocabulario en lengua castellana y mexicana, ${ }^{1}$ fray Bernardino de Sahagún (c1499-1590) en su Historia de las cosas de la Nueva España ${ }^{2}$ y fray Andrés de Olmos ( $\uparrow 1571)$, en el vocabulario de verbos nahuas ${ }^{3}$ que se le atribuye, hicieron referencias a los usos metafóricos idiosincrásicos de la lengua náhuatl. El hecho de que estos autores distinguieran este rasgo al traducir del náhuatl al castellano constituye una innovación para la historia de las ideas lingüísticas. ${ }^{4}$

En este trabajo me propongo describir las referencias al lenguaje metafórico en la obra de estos franciscanos ${ }^{5}$ en función de la distinta tipología textual que presentan las obras mencionadas y a la luz de la tradición renacentista en la que estas se sitúan. Para su contextualización histórica examinaré otros vocabularios hispano-amerindios contemporáneos, así como algunos textos españoles de género lexicográfico de la tradición textual hispánica. Con todo, trataré de mostrar el interés que tiene el hecho de que las obras lexicográficas de los autores franciscanos de la Nueva España hicieran referencias al recurso metafórico a propósito de una lengua indígena.

\section{Antecedentes}

En términos generales, los diccionarios bilingües sirven para traducir palabras o frases de una lengua a otra y normalmente presentan indicaciones gramaticales, de uso, o de estilo, que ayudan al hablante no nativo a emplear una palabra o frase en la otra lengua. Desde luego, los vocabularios bilingües del español con las lenguas indígenas americanas que se compilaron en la época colonial ofrecían abundante información gramatical, ${ }^{6}$ y sus autores hacían también consideraciones sobre el uso ${ }^{7}$ e, incluso, alusiones a la variedad dialectal o social de las lenguas indígenas. ${ }^{8}$ Como es lógico, tales precisiones lingüísticas iban destinadas a los usuarios que entonces tenían la necesidad de trasladar una lengua a otra, mientras que hoy esta información puede resultar muy útil para la descripción de las lenguas, ${ }^{9}$ para la historia de la lingüística, ${ }^{10}$ así como para el conocimiento de determinados aspectos interlingüísticos.

Los autores de las gramáticas y vocabularios coloniales, y en general de las compilaciones bilingües, fueron habitualmente religiosos formados en la Europa renacentista, en donde existía una preocupación por la cuestión de la lengua. Una de las ideas 
lingüísticas predominantes llevaba a emparentar las lenguas romances con el latín; en este sentido, la obra gramatical y lexicográfica de Antonio de Nebrija (1441-1522) fue la más influyente en la lingüística hispánica. ${ }^{11} \mathrm{Al}$ mismo tiempo se hicieron obras en la Europa renacentista que situaban en paralelo varias lenguas con el fin de establecer el prestigio mediante la comparación; este es el espíritu que tiene el Calepino (Dictionarium septem linguarum, Reggio, 1502), la famosa obra del lexicógrafo italiano Ambrogio Calepino (c1440-1510)..$^{12}$ Resultado de esta doble tendencia es que las lenguas romances adquieren su lugar en la lengua escrita, con la composición de la primera gramática de una lengua vulgar publicada en Europa, la célebre Gramática castellana de Nebrija publicada en 1492. Lenguas romances como la francesa y la española, por ejemplo, aparecen por vez primera confrontadas en 1526 en el Vocabulario de cinco lenguas Latina, Italiana, Francesa, Espagnola \& Alemana, publicado en Venecia por Francesco Garrone (Bruña Cuevas $2008,38)$. Se trata, sin duda, de un periodo muy productivo para la lexicografía europea, rica en obras plurilingües y en compendios léxicos eminentemente prácticos, destinados a viajeros y comerciantes principalmente (Hartmann 1986).

\section{El vocabulario bilingüe de Alonso de Molina}

Dentro de ese contexto, que podríamos llamar comparatista entre lenguas o variedades lingüísticas, aparece la lexicografía hispano-amerindia guardando - como se comprobarácierta armonía con la lexicografía bilingüe europea, si bien la americana dará sus primeros pasos respondiendo a las necesidades de usuarios diferentes. Así, con Molina a la cabeza por ser el autor del primer diccionario impreso en el Nuevo Mundo (Molina 2001 [1555]), los productos lexicográficos coloniales hispano-amerindios surgen como herramienta de apren-dizaje de las lenguas indígenas para facilitar las prácticas evangelizadoras. En los prólogos se expresa de manera inequívoca que los destinatarios de los diccionarios son 'los ministros desta yglesia' y que su función es que los religiosos 'entiendan muy bien' la lengua indígena, de modo tal que la evangelización sea más eficaz y provechosa:

Y porque el lenguaje y frasis destos naturales [especialmente de los Nauas y Mexicanos] es muy diferente del lenguaje y frasis latino, griego y castellano, y vuestra Excelencia desee mucho, que los ministros desta yglesia entiendan muy bien la lengua delos dichos naturales, para honra y gloria de nuestro Señor, y para prouecho spiritual y saluacion desta gente: demanera que sean mejor y mas enteramente instruydos y doctrinados en nuestra sancta Fee catholica: ha sido esta la causa y razon [Excelentissimo principe] que me ha mouido, segun la gracia y talento, que nuestro Señor me ha comunicado, a atreuerme y presumir dedicar y ofrecer a vuestra excelencia estos dos Vocabularios. (Molina 1571, Epistola Nvncvpatoria al muy Excelente Señor Don Martin Enriquez, Visorrey desta nueua España)

Por otro lado, el tema de la diversidad lingüística está plenamente vigente en las reflexiones que en el Renacimiento se hicieron los gramáticos y lexicógrafos hispánicos en sus obras (Taboada Cid 1989). Y este será también el trasfondo intelectual en el que los autores de obras bilingües en América elaboraron su obras, cuya difusión se vio notablemente favorecida en algunas áreas americanas por la temprana fundación de la universidad (Sánchez Vázquez 2002) y el establecimiento de la imprenta. Un claro exponente de este espíritu trasplantado al Nuevo Mundo fue la figura del franciscano fray Bernardino de Sahagún, que había estudiado en la Universidad de Salamanca, centro de irradiación del Renacimiento en España, y cuyo espíritu humanista presidió su obra bilingüe del español y el náhuatl (León-Portilla 1999). 
Por su parte, fray Alonso de Molina trató diversos aspectos relacionados con la cuestión de la lengua propios de la mentalidad renacentista, mencionando por ejemplo las dificultades a las que se había tenido que enfrentar para redactar su vocabulario bilingüe de la lengua castellana con el náhuatl en su edición de 1571 (Molina 2001). En primer lugar, se refirió a lo que hoy denominaríamos su competencia traductora, planteando los problemas derivados de que el náhuatl no fuese su lengua materna, siguiendo el tópico de la lengua adquirida por la vía materna ${ }^{13}$ y dando cuenta de cómo la había adquirido. Fue precisamente en la descripción de la lengua meta, según los usos humanistas de ponderación positiva de las lenguas vulgares-en este caso, aplicados a una lengua indígena-, cuando trató el tema de la metáfora:

Algunas dificultades que se me han ofrecido an sido causa que antes de agora no aya puesto mano enesta obra. Lo primero y principal por no auer mamado esta lengua con la leche, ni ser me natural, sino auerla aprendido por vn poco de vso y exercicio, y este no del todo puede descubrir los secretos que ay enla lengua, la qual es tan copiosa, tan elegante, $y$ de tanto artificio y primor en sus metaphoras y maneras de dezir, quanto conoceran los que enella se exercitaren. (Prólogo al lector)

Alonso de Molina nació en España y se trasladó a la Nueva España cuando era un niño. El hecho de que conviviera desde edad temprana con los indígenas hizo posible que aprendiera muy bien el náhuatl y que sirviera a los frailes como intérprete, llegando a ser el más reconocido autor de obras bilingües con esta lengua. ${ }^{14}$ Es bien sabido que los hablantes bilingües vinieron a desempeñar un papel clave en la comunicación entre españoles e indígenas. En el caso de Molina, su labor fue decisiva para la creación de herramientas que facilitaran el aprendizaje de las lenguas indígenas. ${ }^{15}$ Se entiende, por lo tanto, que por ser bilingüe Molina fuera un autor muy cualificado para la traducción entre el español y el náhuatl. De hecho, resulta evidente que procuró y en gran medida logró que no se perdiera significado en el trasvase interlingüístico que implica el proceso de la traducción, ya fuera en la significación común, ya en las suposiciones culturales e intralingüísticas que conllevan los sentidos figurados y las metáforas, puesto que sigue siendo un diccionario de referencia para conocer el náhuatl clásico, e incluso referencia para la dialectología del náhuatl moderno (Canger 1988).

La alusión al lenguaje metafórico que hace Molina es un asunto lingüísticamente no trivial, pues identificar y traducir metáforas de una lengua a otra puede ser una labor complicada, entre otras razones porque a menudo son sutiles y fácilmente pueden pasar desapercibidas. Pero además, saber detectarlas puede ser un indicador de su nivel de competencia de la lengua meta, que se puede entender y explicar desde su condición de sujeto bilingüe. Molina señaló de manera sistemática las metáforas de la lengua indígena dentro de la parte mexicano-castellana del vocabulario. ${ }^{16}$

Por otro lado, Molina proporcionó información directa sobre los problemas que implicó dar las equivalencias semánticas de una lengua a otra. Además de la primera dificultad expuesta en la cita anterior, argumentó que la variedad diatópica de la lengua nahua era también un obstáculo: 'auerseme puesto delante la variedad y diuersidad que ay enlos vocablos, por que algunos se vsan en vnas prouincias, que no los tienen en otras, y esta diferencia, solo el que ouiesse biuido en todas ellas la podria dar a entender' (ibídem). Expresó asimismo diversos problemas producidos por la falta de correspondencia de la lengua fuente con la lengua meta, y a la inversa; dificultades que 
están relacionadas con problemas léxico-semánticos, como las lagunas semánticas y los neologismos:

haze dificultad y no pequeña tener nosotros muchas cosas que ellos no conoscian, ni alcançauan: y para estas no tenian ni tienen vocablos proprios: y por el contrario, las cosas que ellos tenian de que nosotros careciamos en nuestra lengua, no se pueden bien dar a entender, por vocablos preciosos y particulares: y por esto assi para entender sus vocablos como para declarar los nuestros, son menester algunas veces largos circunloquios y rodeos. (ibídem)

Molina aludió también a los procesos de cambio habidos en la lengua náhuatl por la influencia del español, concretamente a los préstamos:

$[\mathrm{T}]$ ambien se ponen en ambos vocabularios, algunas noticias compuestas de nuestro romance y de la lengua mexicana, las quales los naturales han assi compuesto a causa de no tener ni vsar ellos antiguamente de algunas cosas que agora vsan. Exemplo. Nitelcalçascopina, que quiere dezir, descalçar o quitar las calças a otro. Ninocamisatia. \&c. las quales composiciones estan tan vsadas que no las dizen de otra manera: y por esta razon, las devemos tambien nosotros vsar dela misma manera que ellos las vsan. (aviso noveno del prólogo mexicano-castellano)

En definitiva, Molina se planteó reflexiones sobre temas que hoy corresponden a temas centrales de la investigación lingüística, derivados de la variación en el lenguaje y la diversidad lingüística, y que estaban también vigentes en la mentalidad renacentista de los gramáticos europeos.

\section{Otros (ocho) vocabularios hispano-amerindios}

Los vocabularios coloniales de los siglos XVI y XVII poseen características muy similares en lo que respecta a su macro- y microestructura. Para la identificación de las alusiones al lenguaje metafórico de las lenguas indígenas en prólogos de los diccionarios, voy a mencionar ahora sólo sus rasgos esenciales. En primer lugar, la mayoría de los vocabularios que lograron imprimirse presentan primero normalmente la castellana como lengua de partida y las equivalencias en la indígena. Ello es así porque tienen como modelo el Vocabulario español-latino de Nebrija (c1495), algunos de ellos a través de Molina (ver Smith-Stark 2009). Además, siempre tienen como destinatarios los propios frailes, como ya se ha señalado y veremos en algunas citas más adelante. Los vocabularios contienen, por otra parte, información interna de tipo lingüístico e histórico, poniendo de manifiesto la situación sociocultural de cada una de las lenguas enfrentadas. ${ }^{17}$ Por estas propiedades y en muchos sentidos, podemos hablar de una tradición lexicográfica colonial americana en lo que a la producción de vocabularios bilingües hispano-amerindios se refiere, que se manifiesta en la existencia de una red de influencias en cuanto a concepción y técnica de elaboración (Hernández 2008b, 2013). En este sentido, cabría encontrar en ellos marcas sobre los usos metafóricos de las lenguas indígenas, sobre todo en una práctica como la lexicográfica, donde lo normal es que se copien unos autores a otros.

Así, he buscado alusiones al lenguaje metafórico en diccionarios que siguieron al diccionario de Molina: el Diccionario de la lengua tarasca o de Michoacán de fray Maturino Gilberti (1559), el Vocabulario en lengua çapoteca de fray Juan de Córdova (1578) y el Vocabulario en lengua mixteca del dominico fray Francisco de Alvarado (1593). Por otro lado, he analizado también los vocabularios de las lenguas de América del Sur, los 
del quechua de los franciscanos fray Domingo de Santo Tomás (Lexicón, o vocabulario de la lengua general del Perú, 1560) y el Anónimo conocido por el nombre de su impresor Antonio Ricardo (Arte y vocabulario en la lengua general del Perú, llamada Quichua, y en la lengua española, 1586), así como los diccionarios de los jesuitas P. Diego González Holguín (Vocabulario dela lengua general de todo el Peru llamada lengua Qquichua, o del Inca, 1608), el del P. Ludovico Bertonio (Vocabulario de la lengua aymara, 1612) y el vocabulario (no el tesoro) del P. Antonio Ruiz de Montoya (Arte y bocabvlario de la lengva gyarani, 1640).

Pues bien, ninguno de estos diccionarios contiene referencias a las metáforas en sus prólogos. La cuestión entonces que se plantea es ¿por qué Molina tuvo en cuenta esta cuestión? En el apartado siguiente, trataré de responder a esta pregunta. Previamente, y a continuación, voy a dar cuenta a modo de ejemplo de algunas de las reflexiones lingüísticas que contienen estos vocabularios, las cuales también entroncan con las preocupaciones de la época.

La mayoría de estos autores mencionó diversos aspectos de lexicografía práctica, como los que pueden dar lugar a ambigüedad tocantes a la sinonimia y la polisemia; por ejemplo, en el Vocabulario de la lengua misteca (1581), Alvarado señalaba que: ' ... puedo yo dezir de la [lengua] misteca: que demas de sus varias equiuocaciones tiene circunstancias de tanto cuidado y estudio, que haze muy digno de estimar el trabajo delos predicadores y ministros, que han podido subjetarla' (Prólogo al lector).

Por su parte, Córdova, en su Vocabulario de la lengua çapoteca, advertía de la diversidad entre las lenguas, percibiendo diferencias lingüístico-culturales entre la lengua zapoteca y el castellano en el proceso de la traducción. Por un lado, nota las lagunas léxico-semánticas que detecta:

en que estos Indios çapoteca, aun a las cosas que nunca gentes les aplicaron nombres, se le dan ellos, v.g. quien vido dar nombre à el sonido de la campana .s. lo que dizque dizen quando suena, y a lo que haze la culebra quando anda, y a la carreta quando rueda, y a los latidos de los pulsos, y del coraçon, y al heruor de la olla, y aotras cosas assi semejantes, $\mathrm{y}$ aun a los actos que hazen las aues y animales, y a las demas cosas inanimadas. Y a lo que hazen los instrumentos con que hazemos algo, para todo hallan nombres ó interjecciones con que las explicar. (Prefactio al estvdioso lector, aviso I)

Y en la otra dirección también percibe las diferencias:

y muchas cosas, que los Indios hablan, no se pueden reducir a los vocablos generales nuestros. Y assi fue necessario para poderlos explicar, de suerte que se entendiessen, que se pusiessen ó en vocablos particulares, por sy ó por circunloquios, porque, de otra manera, ó se careciera dellos ò no pudieran ser entendidos. (ibídem)

Sin duda, los lingüistas religiosos se esmeraron en explicar lo mejor posible las propiedades de las lenguas de las que hacían inventario léxico y suele ser habitual que también acudan a determinados tópicos renacentistas, haciendo reflexiones idiosincrásicas de la naturaleza, perfección y propiedad de las lenguas indígenas, en claro paralelismo con lo que se estaba haciendo en Europa con respecto a la descripción y el estudio de las lenguas vulgares, según ya he señalado antes. Por este motivo, si tenemos en cuenta que sus compilaciones bilingües tenían como destinatarios a los mismos religiosos, esto es, se dirigían a sus compañeros de orden, hombres cultivados con formación humanista, en la experiencia intersubjetiva que implica dar equivalencias de una lengua a otra, hay que inferir que el 
productor del diccionario está pensando en que tiene por receptor a un igual, esto es, un individuo europeo con sus mismas características socioculturales. En los prólogos sistemáticamente nombran a sus compañeros de orden como los futuros lectores o usuarios de sus productos lexicográficos. Así, en su vocabulario de la lengua quechua, el jesuita González Holguín explicaba que la finalidad del vocabulario era la de: 'ayudar a formar ministros del Euangelio para los indios, dandoles la copia [lo que hoy denominaríamos el léxico] y propriedad [semántica] de la lengua que faltaua, conque no tengan ya alguna excusa para no predicar' (Prefacio). Conviene insistir en el hecho de que los autores confiesen que hicieron sus diccionarios teniendo en cuenta que tendrían como lectores específicos otros religiosos que los usaban para la evangelización, ya que es importante a la hora de comprender el sentido de las alusiones a las metáforas de Molina, en tanto iban dirigidas a los propios religiosos, con los que compartían un bagaje cultural muy semejante.

Por último, hay que señalar que estos autores suelen explicar que reunieron y describieron las palabras o frases de los idiomas vivos, recogiendo formalmente sus reglas gramaticales o inventariando su léxico, con el mismo espíritu que alentó la descripción de las lenguas vernáculas en el Renacimiento. Son, en este sentido, diccionarios apegados al uso cotidiano de la lengua y, por lo tanto, desempeñaron una función lingüística descriptiva (no prescriptiva) de las lenguas autóctonas de América, con el propósito, en última instancia-conviene insistir-, de lograr ser más eficaces en las tareas fundamentales de la evangelización (la predicación y la confesión).

\section{La singularidad de las alusiones a la metáfora en la obra de los franciscanos}

Realizado el análisis de la información metalingüística contenida en los prólogos de vocabularios hispano-amerindios de los siglos XVI y XVII, se constata que sólo el franciscano Molina hace referencias explícitas en torno a esta figura o tropo. Molina es precursor, por tanto, en advertir de la existencia del recurso metafórico y en introducir esta marca de uso en las definiciones, pero no sólo en América, sino que esto ocurre también dentro del conjunto de la lexicografía hispánica que sigue la misma tradición de los vocabularios bilingües del Renacimiento. ${ }^{18}$ El hecho es que no la recoge su fuente principal, esto es, el Vocabulario español-latino de Nebrija de c1495 (Hernández 2000). ${ }^{19}$

Que no haya menciones al uso metafórico del lenguaje en los diccionarios bilingües del siglo XVI con el español y otra lengua no debe extrañarnos y se puede explicar, de alguna manera, por qué metáfora es un cultismo del siglo XV. ${ }^{20}$ En su diccionario histórico-etimológico, Corominas y Pascual (DCEC, s.v. preferir) datan su primera documentación hacia 1440 en Alfonso de la Torre, la cual se puede adelantar con otro testimonio del Cancionero de Baena (apud el CORDE). ${ }^{21}$ Según los datos del nuevo tesoro lexicográfico del español (NTLLE), el primer diccionario bilingüe que introduce metáfora como lema es Minsheu en $1599 ;^{22}$ de hecho, señala Corominas que metáfora 'falta todavía en C. de las Casas [1570]' (ibid). En las obras españolas de contenido lingüístico o lexicográfico del último cuarto del siglo XVI, encontramos las primeras alusiones a esta figura del lenguaje en obras algo posteriores al vocabulario de Molina. ${ }^{23}$

Realmente, la primera referencia al lenguaje metafórico en un texto lingüístico descriptivo lo encontramos en el manuscrito del vocabulario de Olmos estudiado por Sullivan (1985) y atribuido al franciscano fray Andrés de Olmos hacia $1547 .^{24}$ Su octavo capítulo, 
titulado '[D]e las maneras de hablar q[ue] tenia[n] los viejos en sus pláticas antiguas', contiene: '[L] as siguientes man[er]as de [ex]pr[esion]son methaphoricas porq[ue] vna cosa $\mathrm{q}$ [ui]ere dezir laletra y otras la sentenci[a] aunque algunos vayan ala letra glosados y otros se pueden aplicar a otro se[n]tido del que van'. Se trata, pues, del primer testimonio alusivo al concepto de la metáfora en la práctica de la traducción en la Nueva España. ${ }^{25}$ Más adelante (apartado 7) veremos que esta forma de mención de Olmos no difiere de la que pocos años más tarde hará fray Bernardino de Sahagún en su Historia. ${ }^{26}$ Por su parte, en la obra del dominico fray Diego Durán $(\dagger 1588)$ también encontramos una descripción relacionada:

[T]odos los cantares de estos son compuestos por unas metáforas tan oscuras, que apenas hay quien las entienda, si muy de propósito no se estudian y platican para entender el sentido de ellas. Yo me he puesto de propósito a escuchar con mucha atención lo que cantan, y entre las palabras y términos de las metáforas y paréceme disparate, y después, platicado y conferido, son admirables sentencias así en lo divino que agora componen, como en los cantares humanos que componen. ${ }^{27}$

Todo indica que se trata de una práctica en los estudios en torno a lengua náhuatl iniciada por los franciscanos. Veremos que hay menciones a las 'maneras metafóricas' en los trabajos bilingües de fray Andrés de Olmos, de fray Alonso de Molina y de fray Bernardino de Sahagún, influencia que va más allá de la tradición franciscana, puesto que también las encontramos en la obra del dominico fray Diego Durán. ${ }^{28}$

En el apartado siguiente trataré de explicar el tratamiento que hace Molina de este rasgo de la lengua náhuatl en su vocabulario y lo contrastaré con el que ofrece fray Bernardino de Sahagún en su obra enciclopédica, la Historia. Previamente haré algunas consideraciones en torno al concepto sobre la metáfora en la lingüística actual. Mi intención es tratar de determinar qué entendían estos autores por 'maneras de expresión metafóricas ${ }^{29}$ y por qué recurrieron a esta denominación trópica. ${ }^{30}$

\section{La metáfora como problema en la traducción}

300 La metáfora no es simplemente un aspecto ornamental del lenguaje, como ha postulado la teoría poética y la retórica durante siglos, sino un esquema fundamental por el cual el hablante conceptualiza el mundo y sus propias actividades (Gibbs 2008). Esta es básicamente la idea que sostienen Lakoff y Johnson (1980) desde la lingüística cognitiva, en su obra Metaphors We Live By. Es decir, la metáfora no se da primariamente en el lenguaje, sino en el pensamiento; entendemos el mundo a través de metáforas y no sólo hablamos con ellas (Kövecses 2005, 2). En este sentido, las distintas lenguas y culturas puestas en relación en el acto de la traducción pueden revelar visiones del mundo diferentes y, de manera específica, el recurso metafórico pone de manifiesto la diversidad interlingüística. Según Kövecses los modos de ver el mundo que comparten los miembros de una cultura individual a menudo pueden ser visiones metáforicas; si consideramos que las diversas culturas poseen visiones del mundo singulares, así como objetos naturales y culturales propios, el recurso metafórico revela, por un lado, la identidad intralingüística, y, al mismo tiempo, se hace eco de dicha diversidad interlingüística. En el caso que nos ocupa de las obras hispano-amerindias, la traducción de palabras que denotan entidades naturales o culturales propias de una lengua o cultura determinada obviamente entraña dificultades. Pero esto no sucede sólo con las entidades culturales específicas sino 
también ocurre con los conceptos universales-como trato de mostrar a continuación mediante el caso del concepto 'oreja', que aparece en un artículo del vocabulario de Molina.

La ausencia de una visión compartida del mundo entre la lengua castellana y el náhuatl se detecta a partir de la observación de determinadas anomalías gramaticales y semánticas en el texto castellano, que no son otra cosa que el resultado de realizar una traducción literal, también denominada calco semántico o de traducción. Por ejemplo, en el vocabulario de Molina aparece el artículo siguiente:

Tenacaztitechninopiloa. asirse delas orejas de alguno, o reprehender y corregir a otro. [ ... ] Metaphora. (f. 98r)

La frase asirse delas orejas de alguno es inapropiada en el español: no hay documentación histórica ni dialectal en donde el verbo $\operatorname{asir}(s e)$ se relacione léxicamente con el nombre oreja. Sin duda, se trata de una metáfora transparente y fácilmente comprensible, en la cual la 'cabeza' humana se identifica con un 'recipiente' cuyas 'asas' equivalen a las 'orejas'; sin embargo, la frase no se documenta en ningún texto español, seguramente porque la configuración semántica lo impide. ${ }^{31}$ Tampoco la combinación de esas dos palabras en castellano adquiere el sentido de 'reprehender a otro' que posee el náhuatl. ${ }^{22} \mathrm{De}$ hecho, Molina hace una traducción literal del náhuatl al castellano, pero percibe el desajuste entre las dos lenguas y por ese motivo introduce una marca en la definición castellana al ver la imposibilidad combinatoria entre ese verbo y nombre, señalando que se trata de un uso metafórico propio de la lengua náhuatl. Aun pudiendo ser la metáfora clara, se han trasladado las partes constitutivas de una palabra o frase de la lengua indígena de manera insatisfactoria, precisamente porque tales estructuras, por tener una base o motivación figurada o metafórica, producen un evidente desajuste gramatical y semántico entre las dos lenguas puestas en contacto en el acto de la traducción.

Con este mismo concepto se documenta la frase soplar a la oreja con la significación de 'adular', expresión que aparece como equivalencia de una expresión maya en el ms. Codex Indicus 8 del vocabulario maya-español depositado en la biblioteca John Carter Brown (Hernández 2008a, 117). Como en el caso anterior, esa frase no tiene documentaciones ni históricas ni dialecles. Esta vez, sin embargo, el lexicógrafo anónimo del vocabulario maya manuscrito (probablemente fray Alonso de Solana, ibidem) no tuvo ni la conciencia lingüística de Molina a la hora de percibir la anomalía en el castellano, ni consecuentemente la consideración hacia el usario de su diccionario, pues no dio explicaciones de que se trataba de un sentido figurado o metafórico en la lengua indígena.

Estos ejemplos muestran que este concepto, que pertenece al campo semántico del cuerpo humano y es objeto de diversas metáforas en todas las lenguas, ${ }^{33}$ posee un valor simbólico notablemente diferente en la lengua nahua, el maya yucateco, y el español, y puede dar problemas en la traducción. ${ }^{34}$

\section{Alusiones a la metáfora en la obra de Sahagún y de Molina}

Como es sabido, los doce libros de la Historia general de las cosas de la Nueva España de fray Bernardino de Sahagún proporcionan información enciclopédica sobre la religión, la historia, la cultura y la sociedad aztecas. Esta obra monumental sobre la cultura nahua tiene además un reconocido valor lexicográfico, puesto que proporciona alrededor de 
cuatro mil voces nahuas acompañadas aproximadamente de veinte mil definiciones distintas, según ha mostrado Máynez $(1999,2002) .{ }^{35}$ En palabras del propio Sahagún, la obra estaba concebida como 'una red barredera para sacar a luz todos los vocablos de esta lengua con sus propias y metaphoricas significaciones y todas sus maneras de hablar', donde se advierte su preocupación por el sentido no literal durante el ejercicio de la traducción. ${ }^{36}$ Sahagún dedicó una amplia sección del Códice florentino a diferenciar y enlistar de manera ordenada diversas 'metáforas ${ }^{37}$ con un procedimiento semejante al empleado por Olmos en su vocabulario. El capítulo cuarenta y tres lo dedica a '[D]e algunas metáforas delicadas con sus declaraciones'. Su método consiste en dar una primera traducción literal, lo que él denomina 'letra', para explicar a continuación su sentido figurado o metafórico, lo que denomina 'metáfora'. Luego ofrece frases y proberbios del náhuatl para elucidar la significación. En resumen, los mismos elementos se distinguían en el texto de Olmos arriba citado.

Con objeto de describir el procedimiento sahaguntino y contrastarlo con el de Molina, a continuación transcribo una de las metáforas de dicho capítulo: ${ }^{38}$

Téuatl, tlachinolli. Quiere dezir esta letra: El mar o la chamusquina vino sobre nosotros, o pasó sobre nosotros. Por metáfora se dize de la pestilencia o guerra que cuando se acaba dizen: otonpanquiz in téuatl in tlachinolli: Pasó sobre nosotros la mar y el fuego.

Por su parte, Molina define el concepto azteca atl tlachinolli con el significado de 'batalla o guerra' (f. 8v). Atl-tlachinolli está compuesto del náhuatl atl, agua y tlachinolli, 'cosa quemada'. Se trata de un concepto basado en el difrasismo de 'agua' y 'fuego', dos elementos físicamente opuestos, y que significó para los aztecas 'la guerra sagrada'. Este concepto fue plasmado iconográficamente en códices, esculturas y probablemente más objetos, así como mencionado en testimonios posteriores sobre su cultura. Para el mismo, Molina da la marca de uso metafórico de la entrada en atl chinolli, de donde se puede reconstruir el significado literal de sus componentes. ${ }^{39}$

Ambos autores coinciden en mencionar la metáfora en torno al mismo concepto, lo que pone de manifiesto la existencia de una tradición a la hora de explicar los aspectos metafóricos de la lengua nahua en las prácticas traductológicas, con una actuación innovadora dentro del contexto de las obras lexicográficas de la época, según ya se ha señalado. El procedimiento que siguen, sin embargo, es distinto y la diferencia técnica consiste en que Sahagún da la denotación de la frase y sus sentidos literal y figurado en un discurso no conciso con el fin de facilitar la comprensión. En cambio, Molina da la definición sin referir el sentido literal en náhuatl. Evidentemente, Molina no hace un ejercicio de traductor primario como Sahagún, sino que ejerce como lexicógrafo, aportando directamente el significado (o la connotación), pero nos advierte de los usos metafóricos que pueda tener la palabra o la frase en cuestión; para conocer los valores denotativos, debemos acudir al lema correspondiente de su diccionario.

Lógicamente, la divergencia en el tratamiento de la metáfora entre Molina y Sahagún se justifica por el distinto tipo de texto que produjeron-diccionario en el caso de Molina y enciclopedia o estudio etnográfico en el de Sahagún. Los dos franciscanos perseguían objetivos diferentes. Molina produjo una herramienta para ayudar a otros religiosos a codificar y descodificar textos orales o escritos del castellano al náhuatl y del náhuatl al castellano, mientras que Sahagún produjo un estudio etnográfico de carácter didáctico, intercultural e interlingüístico, con el fin de que su obra sirviera a sus compañeros de orden para conocer 
el mundo azteca, su lengua y cultura. En cualquier caso, ambos tenían la misma finalidad de lograr avanzar en su misión evangelizadora.

\section{Conclusiones}

En este trabajo he buscado referencias al uso metafórico del lenguaje en los vocabularios bilingües más conocidos del español con las lenguas indígenas americanas y he comprobado que sólo fray Alonso de Molina, en su Vocabulario en lengua castellana y mexicana (México 1555, 1517), hizo alusión a las metáforas de la lengua náhuatl. He visto que esta práctica lexicográfica resulta innovadora dentro de la lexicografía bilingüe de la época ya que su fuente primordial, el Vocabulario español-latino (c1495) de Nebrija, no contenía ninguna marca de uso metafórico.

Buscando los antecedentes de esta práctica lexicográfica, he tratado de dar cuenta de la relación de los vocabularios bilingües hispano-amerindios con la lexicografía europea. He mostrado cómo algunas de las ideas humanistas que circulaban en España respecto de la cuestión de la lengua, y en torno a la variedad y la diversidad lingüística, tienen su reflejo en América en dichos vocabularios, que fueron redactados por religiosos formados en Europa, para sus propósitos evangelizadores. Por otro lado, he comprobado que hubo una tradición en los estudios lingüísticos sobre el náhuatl durante la segunda mitad del siglo XVI, que tuvo su reflejo en las compilaciones bilingües de los franciscanos. Esta tradición, entre otros aspectos, se materializó en la coincidencia en el tratamiento del lenguaje metafórico de esa lengua indígena. Quien primero hizo referencias a las características metafóricas del náhuatl fue fray Andrés de Olmos en su vocabulario de verbos y hallamos una práctica semejante en el Códice florentino de fray Bernardino de Sahagún.

Alonso de Molina fue precursor en la lexicografía de la época al referirse al problema de la metáfora en el prólogo de su diccionario bilingüe, el Vocabulario en lengua castellana y mexicana (México 1555). Y lo fue también desde el punto de vista técnico, al introducir la marca lexicográfica de uso metafórico en la parte mexicano-castellana de su diccionario (ed. México 1571). En mi opinión, además de las posibles influencias que pudo tener por parte de sus antecedentes europeos y de sus predecesores (quizás de Olmos), el hecho diferencial que puede explicar la novedad estriba en que fray Alonso dispuso de más recursos para la traducción que otros lexicógrafos del momento. Ser un hablante bilingüe, que había adquirido el náhuatl siendo un niño, hizo que su competencia lingüística fuese más cualificada que la de otros autores de vocabularios bilingües hispánicos, como la de los religiosos que compilaron los vocabularios hispano-amerindios durante la época colonial, los que, normalmente procedentes de España (o Italia, en algunos casos), aprendieron la lengua indígena siendo ya mayores. De este modo, su dominio de las dos lenguas permitió a Molina controlar las metáforas del náhuatl y, a la vez, realizar una labor reflexiva o metalexicográfica, que puede considerarse innovadora dentro de la lingüística hispánica del momento.

\section{Agradecimientos}

Este trabajo se ha realizado en el marco del proyecto FFI2011-29259 y ha contado con el beneficio de dos revisores anónimos para su publicación en esta revista. A ellos agradezco profundamente su atenta lectura y atinadas sugerencias, que han mejorado de manera 
sustancial el contenido y algunos aspectos de forma de este trabajo; si hay algún error, es sólo atribuible a quien esto escribe.

\section{Notas}

1. Ver Molina 2001 [1555]; íd. 2001 [1571].

2. Obra también conocida como Códice florentino, para la que sigo la edición que reproduce en facsímil el ejemplar conservado en la Biblioteca Medicea Laurenzian, ver. Sahagún 1979 [1578].

3. Ver Olmos 1985 [c. 1547].

4. En lo que podríamos considerar lexicografía (o etnografía) precientífica, se entiende. Por otro lado, se trata de un rasgo en el que la lingüística mesoamericana actual continúa ahondando (Montes de Oca 2004; Monzón 2005).

5. En Lingmex compruebo que hay un estudio de temática semejante, que no me ha sido posible consultar (Montes de Oca, en prensa).

6. Los diccionarios de esta época no son autónomos de la gramática (ver Esparza Torres 1999).

7. Por ejemplo, fray Thomás de Coto, en la definición del verbo asar de su Vocabulario de la lengua cakchiquel o guatemalteca (c. 1650) introducía información práctica con la idea de facilitar el uso de este verbo, de cara a su misión evangelizadora: 'Asar. [ ... ] asar en hoyo cubriendo con tierra lo que asi se asa o como asan las pencas de cabuya o maguei o la danta [... ] para reprehender a estos naturales y darles a entender las penas del purgatorio, es bueno este verbo' (la cursiva es nuestra). En este trabajo sigo un criterio paleográfico de tran-scripción de los textos de las fuentes primarias (como en este caso del vocabulario manuscrito de Coto); por el contrario, transcribo las citas de otros textos según los criterios de las fuentes secundarias en las que me baso. Por este motivo, el lector puede encontrar criterios de transcripción diferentes.

8. Ver infra apartado 3.

9. Los productos lexicográficos han sido analizados como fuentes para conocer la aculturación de las lenguas indígenas (Karttunen 1985) y se han investigado en ellos los distintos procesos de hispanización, que son resultado de las relaciones culturales y lingüísticas, históricamente conflictivas. Se ha atendido a la expansión e influencia del español mediante el estudio de diversos aspectos y fenómenos reflejados en estos textos, que vienen derivados de la situación sociolingüística en la que se encuentran la lengua dominadora (el español) sobre las dominadas (las indígenas). Tales investigaciones han tenido un interesante desarrollo en el nivel gramatical, en particular en el plano fonético-fonológico, pero también en el morfológico y sintáctico. Desde el punto de vista de la semántica o de la pragmática o de la propia disciplina de la traducción, las investigaciones son más escasas. No obstante, Arzápalo Marín (inédito), en el $I V$ Congreso de Lingüística Misionera celebrado en Valladolid (España), trató del dominio o la imposición de las categorías semánticas españolas o del español en el campo religioso y político de los mayas; mostró cómo en algunos textos, como en el Calepino maya de Motul, se apreciaba una semántica implantada por los misioneros de la época colonial en esos campos léxicos concretos. Otros autores (Robles 1964; Schlenther 1968) han abordado también los problemas de la traducción de conceptos filosóficos y religiosos.

10. La subárea de la Historiografía lingüística denominada Lingüística misionera toma las obras de los autores religiosos como fuente para conocer aspectos de la historia de la lingüística y de las ideas lingüísticas (ver Zimmermann 2004; específicamente, en el caso de los diccionarios, ver Zwartjes et al. 2009).

11. Para la repercusión de las ideas y obra de Nebrija, así como su bibliografía, ver Braselmann 1991, Esparza Torres 1995, y Esparza Torres y Niederehe 1999. Para la influencia de Nebrija en la lexicografía románica, ver Colón Doménech 1997 y, específicamente, para su repercusión en la lingüística de América, ver Hernández de León-Portilla 1993.

12. Sobre las ediciones de esta obra, ver Labarre 1975. Otras obras contemporáneas de sesgo similar fueron las de: 'Teseo Ambroggio Albonese: Introductio in Chaldaicam linguam, syriacam atque armenicam et decem alias linguas, Paris, 1539; Konrad von Gessner: Mithridates de 
differentis linguarum, 1555, o la del alemán H. Megiser: Specimen XL ... linguarum et dialectorum, Franckfurt, 1592' (apud Taboada 1989, 77).

13. Para el tópico de la lengua adquirida por la vía de la leche materna, ver Rivarola 2001. Esta idea y la relativa a la diversidad lingüística existente en la Península ibérica circulaba en las gramáticas españolas, p.ej.: 'la lengua natural que deprendian a los pechos de las madres. Exenplo tenemos en Vizcaia, adonde toda la xente mas noble sabe la Castellana, i todos los de maior edad la hablan o entienden, i no dexan la suia, ni pueden; en Valenzia, Cataluña, Portugal es casi lo mesmo' (Correas 1984 (1627), apud Taboada 1989, 88).

14. 'Fray Alonso de Molina vino con sus padres a estas partes de la Nueva España, luego como se conquistó. Y como era de poca edad, deprendió con facilidad la lengua de los indios mexicanos. Y cuando comenzaron los primeros doce padres a cultivar esta viña del Señor, este niño les sirvió de intérprete y enseñó a algunos de ellos la lengua mexicana' (Mendieta 1870 [c. 1596], Historia, libro V). Para una síntesis de los detalles de la vida y obra de fray Alonso de Molina, ver Hernández 1996, 6-15.

15. En el informe que escribió Mendieta en Vitoria en 1570, dirigido al Presidente del Consejo de Indias, puede leerse a propósito de Molina que fue 'confesor y predicador de indios y de españoles. Ha sido y es la mejor lengua mexicana de aquella tierra, mayormente para el uso de la predicación y para tratar con los indios. Ha compuesto muchas cosas buenas en la lengua ...', según el ms. Informe Mendieta.

16. Las marcas de uso alusivas al lenguaje metafórico están en la parte mexicano-castellana del diccionario y, a partir de las mismas, se puede estudiar tanto la visión del hombre europeo en torno a las categorías metafóricas indígenas, como los procedimientos que se emplearon a la hora de dar equivalencias interlingüísticas. En los apartados 6 y 7 analizo algunos casos en la obra de Molina (y también de Sahagún). Para que los especialistas en la lengua náhuatl puedan analizarlas en profundidad, las transcribo a continuación: Cecemotli. persona de mala fama. Metaph. 15r. // Cuzcatl quetzalli. hijos o hijas. Metaphora. 27v. // Icça. niqu. hollar o pisar algo [ ... ] 32r. // Iccemayan mixcoyan moneuian tocomottitiato conmonamctia ynatlauhtli. de tu voluntad y con toda determinacion te echas a perder. Met. // Ima ycxi ytlan caaquia. el que no haze caso de sus deudos por estar el rico. Metapho. 37v. // Matoyauiani. el que cayo en gran delicto. Meta. 53v. // Mitl chimalli. guerra, o batalla. Metapho. 57r. // Mocouiltomnoani. rico. \& per Metapho. El que se goza mucho. 58r. // Momilinoa ynnonetlacuil. ganar conla hazienda que se da alogro. Metapho. 59r. // Motepexiuiani. Despeñado, o el que cometio algun crimen graue. Metapho. 60r. // Notzontecon nelchiquiuh nicqua. Biuir sin sudor y trabajo, o ganar sueldo. Metapho. 74r. // Occhalchiuitl. Es aun donzella y virgen. Metaph. 75r. // Petlapan ycpalpan nica. Tener officio de regir y gouernar. Metaphora. 81r. // Petlatitlan icpaltitla nitlaaquia. encubrir delicto de otro. Metapho. 81r. // Petlatitlan icpaltitlan nitlatlapachoa. Encubrir culpa de otro. Metapho. 81r. // Pinotiliztli. Encogimiento del que es empachoso y vergonçoso. Metapho. 82. // Pocmictia. nitla. Dar pena y enojo a otros. [ ... ] Metapho. 82v. // Quaçacamoa. Nitle. Messar a otro [...] Metaphor. 84r. // Quetzalteuh, cozcateuh ipan nimitzmati. Tener gran amor el padre al hijo. Metaphora. 89r. // Teiçolo. Cosa que ensuzia. Metapho. 94v. // Teixtecanaz. Embaxador, o mensajero. Metaph. 96r. // Tenacaztitechninopiloa. Asirse delas orejas de alguno, o reprehender y corregir a otro. [ ... ] Metaphora. 98r. // Tenacaz. Embaxador, o mensajero de grandes. Metaphora. 98r. Tenacaztitechninopiloa. asirse delas orejas de alguno, o reprehender y corregir a otro. [...] Metaphora. f. 98r. Tenqualactli, yztlactli. Engaño o mentira Meta. 99r. // Tetl quauitl. Enfermedad o castigo. Metaphora. 110v. // Enfermedad. cocoliztli. Et per metaphoram. temoxtli, eecatl. tetl. quauitl. 53r. // Teuicaltia. Nino. Seguir, o imitar al vulgo, haziendo loque los otros hazen. Metaphor. O hazer y procurar que otros me lleuen consigo ensu compañía. [ ... ] 112r. // Teuic temecapal. Esclauo de alguno. Metapho. 112r. // Tlapallieliztli. Nobleza de sangre y de linage. Metaphora. 132v. // Tlapalli tlilli nictlalia. Dar buen exemplo. Metaphora. [ ... ] 130v. // Tiçatl yuitl nictlalia. Dar a otro buen consejo y auiso, o dar buen exemplo [... ] Metapho. 113r. // Tlachinolli teuatl. Guerra o batalla. Metaphora. 117v. // Tlilli tlapalli nictlalia. Dar buen exemplo. [ ... ] Metapho. // Tzimmatoca. Nite. Examinar algun negocio, inquiriendo de como passo, para saber la verdad [... ] Metaphora. 152r. // Tzineua. nite. deponer y quitar a alguno del officio o cargo 
que tenia, o echar a alguno cabeça baxo enel agua, o dela ventana abaxo. [ ... ] Metaphora. 152r. // Tzineua. nitla. asolar y destruir el pueblo. Metaphora. o desarraygar arboles o cosa semejante. [ ... ] 152r. // Xayacatia. nicno. emmaxcararse con ruynes costumbres. [ ... ] Metapho. 158r. // Xocomictia. nitla. dar mal exemplo a todo el pueblo, haziendolo errar. [... ] Meta. 160v. // Xopetlatitlan. nicalaqui. esconderse. Metaphora. [ ... ] 161r.

17. Como es bien sabido, los diccionarios contienen abundante información sobre la lengua y la cultura del momento en que son escritos, ver Considine 2008.

18. Hay, sin embargo, un antecedente dentro de la lexicografía medieval, concretamente en el Vocabularium Ecclesiasticum (Sevilla, 1499), de Rodrigo Fernández de Santaella, obra que tuvo gran difusión y éxito en su tiempo (ver Medina Guerra 2000). En efecto, he localizado tres artículos que contienen la marca interna 'methaphora es', p. ej.: 'senecie. cia. fe. ge. et numen plural: las saliuas o bauas dlos viejos. manducantes senecias. prolo. Ezech.i. mascando las murmuraciones \& detractiones que son como las bauas Methaphora es' (a partir del fichero general, accesible a través de la web del nuevo diccionario histórico del español, http://web.frl. es/fichero.html). A pesar de que en otra ocasión sosteníamos que Molina no lo había empleado (Hernández 2001, 36), este dato plantea la posibilidad de que sí hubiera podido disponer del vocabulario de Santaella.

19. En la gramática castellana había señalado que ' $[M]$ etaphora es cuando por alguna propriedad semejante hazemos mudanza de una cosa a otra como diziendo es un león ...' (Nebrija 1492, lib. 4, cap. 7).

20. Es una palabra que se consolida y difunde a partir del siglo XV, aunque en el banco de datos histórico académico del español (CORDE) hay un testimonio anterior del Cancionero de Baena ('Esta cantiga fizo el dicho Alfonso Álvarez por amor e loores de unas lindas donzellas e damas que andavan con la señora Reina de Navarra, e trae aquí manera de contemplaçión por metáfora de uno que era enamorado e non quiso descobrir quién era su amiga. [1379-a.1425 Villasandino, Poesías]).

21. 1414-a1435 Manuel de Lando, Poesías [Cancionero de Baena] 'más un poco en esta arte fonda e cara, que mi seso aquí compara invençiones entricadas metáforas delgadas a otras gruessas, infladas, , por figuras trasformadas que Dios le muestra e depara'.

22. ' $[\mathrm{M}]$ etáfora, a metaphor, a borrowed speech; metáphora $[\ldots]$, a metaphor, a borrowed speech, when figuratiuely we expresse one thing by naming another'.

23. Por ejemplo, aparecen en el diccionario histórico (DHLE) las documentaciones coetáneas siguientes: 1580 Herrera, Anotaciones 85 ('[L]a catacresis o abusión [ ... ] se diferencia de la metáfora en esta manera: que la abusión es donde falta de todo punto el nombre, i la metáfora donde uvo otro. [s.v. abusión])'; 1593 Guadix, s/v ensayar 391 ('[E]nsayar dizen en España [ ... ], por metáfora, para significar lo que es probar bentura y ber cómo sepone o cómo sale alguna acción humana'); 1596 López Pinziano, Philos. poét. 234 ('[L]a especie última y quarta [de metáfora] se dize analogía, porque passa el vocablo a significar otra cosa, y el vocablo de la otra cosa torna a significar la cosa del vocablo primero. Desta manera dezimos a la poesía pintura y a la pintura poesía, y al escudo copa, y escudo a la copa; assí que en esta especie quarta se doblan las metáphoras siempre, o a lo menos se pueden doblar' [s.v. analogía]; 1601 Rosal ('el Árab[e] dice çaiqcal; parece soncalar, ligeramente encalar, tomada la metáfora de los edificios' [s.v. acicalar]; 1607 De los Ángeles, Consider. Cant. Salomón (NBAE XXIV) $75 a$ 'Es elegante metáfora ésta tomada de las madres, que con los pechos acallan los niños y los consuelan cuando los ven llorando’ [s.v. acción1]; 1603 Luque Faxardo, Desengaño juegos 299 ('La causa destos yerros consiste en no conocer la diferencia entre metáfora y alusión [... ]; alusión es pan casero sazonado y de gusto: causa agrado en el que oye, alienta lo que se dize' [s.v. alusión]. 1609 Yepes, Crón. S. Benito I 62c '[L] lamauan los Griegos Analfabetos a los hombres sin letras; con propriedad, a los que no sabian leer; pero con alguna extensión y metáfora a los que no estudiauan de propósito y que no professauan las ciencias' [s.v. analfabeto]; 1611 Covarrubias, Tes. 14c ('Por metáfora dezimos adelgazar vn punto o questión, ventilándola con sutileza’ [s.v. adelgazar]), 1627 Correas, Refr. (1967) 614b '[A]hogarse en poka agua: Por metáfora, es perder el ánimo en poka difikultad' (s.v. agua 1). 
24. Ver Olmos (1985 [c. 1547]). Por otra parte, Smith-Stark 2009 y Hernández 2005 consideran que este vocabulario manuscrito presenta coincidencias de léxico español con el diccionario de Molina; y, precisamente, esta nueva coincidencia con respecto a las menciones a las metáforas entre Olmos y Molina vendría a confirmar su relación. Dakin (inédito), en cambio, ha planteado dudas razonables de la autoría de Olmos al analizar la parte náhuatl.

25. Ver las críticas que Andrews 1998 realizó sobre la interpretación del concepto metáfora efectuada por Maxwell \& Hanson.

26. Para la discusión sobre la influencia de Olmos en Sahagún, ver Hanson 1994.

27. En Durán 1867, 233; ver también Todorov 2003, 222.

28. Asimismo, encontramos dos ocurrencias que aluden a una lengua indígena americana en la Apologética historia sumaria (1536) del dominico Bartolomé de las Casas: 'despues que cognoscieron sus obras nefandas, escarnecen dellos competilles tal nombre más que al negro Juan blanco, porque ellos tienen sus metáforas y significaciones' (BAE, XIII, 276 apud fichero general de la RAE, ver nota 17).

29. En el caso de Olmos, he hallado cuarenta y tres 'maneras de expresión metafóricas' de tipología diversa y que, por razones de espacio, no podemos tratar ahora, si bien dejamos para un estudio ulterior. Dicho de modo resumido, el procedimiento técnico para consignarlas es el siguiente: tanto las listas léxicas en castellano como sus equivalencias en náhuatl están separadas por calderones; las primeras aparecen tipográficamente distinguidas en texto corrido dentro de un solo párrafo. Por ejemplo, en el segundo ítem o 'manera de expresión' se identifica una 'figura superior familiar, militar o política' con un 'árbol': padre, madre. señor. capitan. governador, que son o estan como arbol d[e]a[m]paro. // tantli. tahtli. xopechtli. manaualli. pochotl. aueuet. caualli a cauh yo. ecauillo. ynitzcallotiac. ym malaca yoticac.// quexane mamalhuaca, tlaçoua. tlapipana. tlamatzin.// chalchiuitl, teoxiuitl, cuizacatl quetzalli altepetl. petlatl. icpapalli. tlauilli. tezcatl. ocotl. tlepilli. machotl. octocotl.

30. La innovación léxica pudo estar motivada por la necesidad de crear una denominación que describiera el tipo de lengua aglutinante que es el náhuatl, en donde, como es sabido, se aglutinan sufijos a una raíz fija que modifican o precisan su sentido. Esto es lo que el notable filólogo e historiador mexicano Ángel María Garibay denominó difrasismos, término que describe un tipo concreto de construcción gramatical en la que dos palabras diferentes, al aparecer juntas, constituyen una tercera unidad de significado con carga metafórica $y$, a menudo, no relacionada con los significados de las dos palabras por separado (Montes de Oca 1997); asunto de índole tipológica que no podemos abordar ahora.

31. He revisado los bancos históricos del español (CORDE, CREA, Corpus del español, LHA y otros) así como el gran macrocorpus del español en google, donde hay más de cuatro billones de registros.

32. En español existe la expresión tirar de las orejas de alguno con el sentido de 'reprehender'. La diferencia semántica es sutil, pero existe y se manifiesta en el nivel gramatical: asirse significa 'agarrarse de algo' y tirar 'estirar, o extender'.

33. Lakoff defendía que los conceptos metafóricos básicos pueden ser universales dado que la experiencia corporal humana es básicamente la misma, pero-según acabamos de ver-un concepto universal 'oreja' puede dar lugar también a diversidad de matices en la concepción interlingüística, y, a su vez, manifestarse en el nivel gramatical y semántico. La investigación de sus valores connotativos permitirá confirmar determinados aspectos sobre la relatividad o la universalidad de las expresiones metafóricas.

34. En el libro editado por Montes de Oca, La metáfora en Mesoamérica, la metáfora se analiza entre hablantes de las familias lingüísticas maya y yutoazteca y en él se trata, fundamentalmente, el asunto de la universalidad de las expresiones metafóricas.

35. Con este valor lexicográfico considero aquí la obra sahaguntina y la hago equiparable a la de Molina.

36. Figueroa-Saavedra (2000) ha planteado las dificultades de traducir las metáforas sahaguntinas.

37. Quizá en la obra de los franciscanos la idea de la metáfora tenga su origen en la influencia de las Etimologías de San Isidoro de Sevilla (c. 556-636), que fue un autor muy leído en el Renacimiento. En este sentido, $c f r$ : '[E] esta manera de fablar que se llama methafora se faze de 
quatro guisas. La una es ab animali ad animal, que quiere dezir "de cosa que ha alma [a cosa que ha alma]", así commo: Aligeros coscendit equos, esto es a dezir: "Cavalga cavallos que han alas"; en este logar fablando por metáfora mezcló alas de ave a la bestia. E commo: "Por corrimiento demandó los desiertos", esto es, que bolando corrió a los desiertos; mezcló el seso, que es de la bestia a la ave. La otra manera se faze de cosa que non ha alma a cosa que non a alma, así commo es aquello: Pontum pinus arat, sulcus premit alta carina, que quiere dezir: "El pino ara la mar e la nave faze sulco en ella”; mezcló aquí el uso de la tierra a las aguas, ca arar e sulco fazer a la tierra pertenesçe e non a la mar. La otra manera de metháfora es de cosa que non ha alma a cosa que ha alma, así commo aquello: Te, Neptune pater, cui tempora cana crepanti cuncta ssalo resonant magnus cui perpete mento profluit Oceanus et flumina crinibus' (h. 1450, Las Etimologías romanceadas de San Isidoro, apud González Cuenca 1983).

38. Para facilitar la lectura, en este caso transcribo el texto castellano modernizando algunas grafías, así como con acentuación y puntuación según el uso actual.

39. Los artículos del diccionario relacionados son los siguientes: Atl. agua, orines, guerra o la mollera de la cabeça. f. 8r. // Chinoa. nitla. quemar los campos. // Tlachinoliztli. el acto de quemar los campos. // Tlachinolli. cosa quemada assi, o chamuscada. // Tlachinolli teuatl. guerra o batalla. Metaphora. Por otro lado, el concepto atl 'agua' está presente en otras frases y normalmente tiene un sentido negativo, lo que hace pensar en el valor simbólico que tiene este concepto en la cultura nahua. Los artículos siguientes quieren decir 'caído en el agua, que se ha ahogado o hundido', literalmente: Atitlanaquia. nic. desperdiciar la hazienda. [...] Metaphor. f. 8r. // Atitlanaquia. nitla. hundir o meter algo enel agua. [...] // Matoyauiani. el que cayo en gran delicto. Meta. f. 53v.

\section{bibliográficas}

Alvarado, Francisco, fray. 1962. Vocabulario en lengua mixteca [1593]. Reproducción facsimilar, con un estudio de W. Jiménez Moreno; apéndice con un 'Vocabulario sacado del Arte en lengua mixteca de fray Antonio de los Reyes'. México D.F.: Instituto Nacional Indigenista e Instituto Nacional de Antropología e Historia.

Andrews, J. Richard. 1998. Reseña a Of the manners of speaking that the Old Ones had: the metaphors of Andres de Olmos in the TULAL Manuscript, 'Arte para aprender la lengua mexicana,' 1547 de Judith M. Maxwell y Craig A. Hanson. International Journal of American Linguistics 64 (3): 292-98.

Anónimo [= Ricardo, Antonio]. 2009. Arte y vocabulario en la lengua general del Perú, llamada Quichua, y en la lengua española [1586]. Ed. Julio Calvo Pérez. Madrid: Agencia Española de Cooperación Internacional para el Desarrollo.

Arzápalo Marín, Ramón. [2007]. El dominio religioso y político de los mayas, a través de la

semántica implantada por los misioneros de la época colonial. Ponencia presentada en el Vth International Conference on Missionary Linguistics [Quinto Congreso Internacional de Lingüística Misionera], Mérida (Yucatán), 14 al 17 marzo 2007.

Bertonio, Ludovico. 1612. Vocabulario de la lengua aymara. Juli: Francisco del Canto.

Braselmann, Petra. 1991. Humanistische Grammatik und Volssprache. Zur "Gramática de la lengua castellana» von Antonio de Nebrija. Dusseldorf: Droste Verlag.

670 Bruña Cuevas, Manuel. 2008. La producción lexicográfica con el español y el francés. Philologia Hispalensis 22: 37-111.

Canger, Una. 1988. Nahuatl dialectology: A survey and some suggestions. International Journal of American Linguistics 54 (1): 28-72.

Codex Indicus 8 = [Solana, Alonso de la, c1580]. Vocabulario muy copioso en lengua española y maya. Ms. en John Carter Brown Library, Brown University, Providence. 
Considine, John. 2008. Dictionaries in Early Modern Europe. Lexicography and the making of heritage. Nueva York: Cambridge University Press.

CORDE. Real Academia Española: Banco de datos [en línea]. Corpus diacrónico del español. <http:// www.rae.es> [06/2013]

Córdova, Juan de, fray. 1987. Vocabulario en lengua çapoteca [1578]. México D.F.: Ediciones Toledo.

Corpus del español. Mark Davies, ed. Corpus del español [en línea]. http://www.corpusdelespanol. org/ [06/2013]

Correas, Gonzalo. 1984. Arte kastellana [1627]. Ed. Manuel Taboada Cid. Santiago de Compostela: Universidad de Santiago de Compostela.

Coto, Tomás de, fray. c. 1650. Vocabulario de la lengua cakchiquel y Guatimalteca, nueuamente hecho y recopilado con summo estudio, trauajo y erudición. Manuscrito depositado en la

American Philosophical Society de Filadelfia, signatura 497.43:C82.

Dakin, Karen. [2007]. La organización de los verbos en el Vocabulario del Ms. del Arte de Olmos en

la Universidad de Tulane. Ponencia presentada en el Vth International Conference on Missionary Linguistics [Quinto Congreso Internacional de Lingüística Misionera], Mérida (Yucatán),14 al 17 marzo 2007.

DCEC. Corominas, Joan, y José Antonio Pascual. 1980-1991. Diccionario crítico etimológico castellano e hispánico. 6 vols. Madrid: Gredos.

Durán, Diego, fray. 1867. Historia de los indios de Nueva España e islas de Tierra Firme [c. 1680]. $<$ http://www.cervantesvirtual.com/FichaAutor.html?Ref=7521>.

Esparza Torres, Miguel Ángel. 1995. Las ideas lingüísticas de Antonio de Nebrija. Münster: Nodus.

- 1999. Gramática y diccionario en las primeras descripciones del español. En Actas del I Congreso Internacional de la Sociedad Española de Historiografía Lingüstica. (A Coruña, 1821 de febrero de 1997), eds. Mauro Fernández Rodríguez, Francisco García Gondar y Nancy Vázquez Veiga, 245-55. Madrid: Arco Libros.

Esparza Torres, Miguel Ángel, y Hans Josef Niederehe. 1999. Bibliografía nebrisense. Las obras completas del humanista Antonio de Nebrija desde 1481 hasta nuestros días. Amsterdam: John Benjamins.

Figueroa-Saavedra, Miguel. 2000. Sustantivos mútilos y su traducción en el Códice Florentino. Revista Española de Antropología Americana 30: 191-220.

Gibbs, Raymond W. Jr. 2008. Metaphor and thought: The state of the art. The Cambridge handbook of metaphor and thought, ed. Raymond W. Gibbs, Jr., 3-17. Santa Cruz: University of California Press.

Gilberti, Maturino. 1901. Diccionario de la lengua tarasca o de Michoacán [1559]. Ed. A. Peñafiel. México D.F.: Tipografía de la Oficina Imp. de Estampillas.

González Cuenca, Joaquín, ed. 1983. Las Etimologías romanceadas de San Isidoro. Salamanca: Universidad de Salamanca-Consejo Superior de Investigaciones Científicas-Institución Fray Bernardino de Sahagún-Diputación Provincial de León.

González Holguín, Diego. 1608. Vocabulario dela lengua general de todo el Peru llamada lengua Qquichua, o del Inca. Lima: Francisco del Canto.

Hanson, Craig A. 1994. Olmos and Sahagún. En Chipping away on Earth: Prehispanic and colonial Nahua studies in honor of Arthur J.O. Anderson and Charles E. Dibble, ed. Eloise Quiñones Keber, 29-35. Culver City: Labyrinthos Press.

Hartmann, Reinhard, ed. 1986. The history of lexicography. Amsterdam: John Benjamins.

Hernández, Esther. 1996. Vocabulario en lengua castellana y mexicana de fray Alonso de Molina. Estudio de los indigenismos léxicos y registro de voces españolas internas. Madrid: Consejo Superior de Investigaciones Científicas.

- 2000. El Vocabulario náhuatl de Molina frente al Vocabulario de Nebrija. Iberorromania 52: $1-19$.

- 2001. Estudio preliminar. En Alonso de Molina, Vocabulario en lengua castellana y mexicana [1571], ed. Esther Hernández, 1-47. Madrid: Agencia Española de Cooperación Internacional. 
2005. En torno al diccionario americano más antiguo: el Vocabulario de verbos nahuas de fray Andrés de Olmos (1547). En Filología y lingüística. Estudios ofrecidos a Antonio Quilis, 2: 1779-96. Madrid: Consejo Superior de Investigaciones Científicas; Universidad Nacional de Educación a Distancia; Universidad de Valladolid.

.2008a. En torno al vocabulario hispano-maya conservado en la biblioteca John Carter Brown (Codex Indicus 8). Revista de Lexicografía 14: 111-22.

- 2008b. La lexicografía hispano-amerindia del siglo XVI. Philologia hispalensis 22: 189-211.

- 2013. Remarks on seventeenth-century bilingual dictionaries of Spanish and indigenous languages of America. Beiträge zur Geschichte der Sprachwissenschaf 23 (1): 103-20.

- 1993. Nebrija y el inicio de la lingüística mesoamericana. Anuario de Letras 31: 205-23. Informe Mendieta = manuscrito depositado en el Instituto Valencia de don Juan (Madrid, España)

titulado Los nombres delos frailes de San Francisco que [estaban] quedaban al principio desde año de 1570. En la provincia de mexico que se llama del santo evangelio y sus calidades son los siguientes ... V. Vitoria, 20 de noviembre de 1570. [signatura: envío 25, documentos 488-499 (493)].

Karttunen, Frances. 1985. Nahuatl and Maya in contact with Spanish. Austin: University of Texas.

Kövecses, Zoltán. 2005. Metaphor and culture. Universality and variation. Nueva York: Cambridge University Press.

Labarre, Albert. 1975. Bibliographie du dictionarium d'Ambrogio Calepino (1502-1779). BadenBaden: Koerner.

Lakoff, George, y Mark Johnson. 1980. Metaphors we live by. Chicago: University of Chicago Press.

León-Portilla, Miguel. 1999. Bernardino de Sahagún, Pionero de la antropología. México D.F.: Universidad Nacional Autónoma de México; El Colegio de México.

LHA = Boyd-Bowman, Peter. 2003. Léxico hispanoamericano (1493-1993), eds. Ray HarrisNorthall y John J. Nitti. CD-Rom. Nueva York: Hispanic Seminary of Medieval Studies.

Lingmex. Bibliografía lingüística de México desde 1980. <http://lingmex.colmex.mx/>

Máynez, Pilar. 1999. Fray Bernardino de Sahagún, precursor de los trabajos lexicográficos del Nuevo Mundo. Estudios de Cultura Náhuatl 29: 189-97.

—. 2002. El Calepino de Sahagún: un acercamiento. México D.F.: Universidad Nacional Autónoma de México; Fondo de Cultura Económica.

750 Medina Guerra, Antonia María. 2000. En torno a la preparación de una edición crítica del

Vocabularium Eclesiasticum de Rodrigo Fernández de Santaella. En Tendencias en la investigación lexicográfica del español: el diccionario como objeto de estudio lingüístico y didáctico, eds. Stefan Ruhstaller y Josefina Prado Aragonés, 137-50. Huelva: Universidad de Huelva.

Mendieta, Gerónimo de, fray. 1870. Historia eclesiástica indiana [c. 1596]. Obra escrita a fines del siglo XVI. Ed. Joaquín García Icazbalceta. México D.F.: Antigua Librería.

Minsheu, John. 1599. A Dictionarie in Spanish and English ... . Londres: Edmund Bollifant.

Molina, Alonso de, fray. 2001. Vocabulario en lengua castellana y mexicana [1571]. Ed. Esther Hernández. Madrid: Agencia Española de Cooperación Internacional.

Montes de Oca Vega, Mercedes. 1997. Los disfrasismos en el náhuatl, un problema de traducción o de conceptualización. Amérindia: Revue d’Ethnolinguistique Amerindienne 22: 31-44.

- En prensa. De metáforas y difrasismos en los vocabularios de Fray Alonso de Molina. Lenguas, estructuras y hablantes. Estudios en homenaje a Thomas C. Smith Stark, eds. Rebeca Barriga Villanueva y Esther Herrera Zendejas. México D.F.: El Colegio de México. 
Monzón, Cristina. 2005. Los morfemas p'urhépechas de trayectoria: espacio, tiempo y metáfora. UniverSOS. Revista de Lenguas Indígenas y Universos Culturales 2: 147-67.

Nebrija, Elio Antonio de. 1989. Vocabulario español-latino [c. 1495]. Madrid: Real Academia Española.

— 1992. Gramática de la lengua castellana [1492]. Ed. Antonio Quilis. Madrid: Ediciones Cultura Hispánica.

Ms. del vocabulario de Olmos = Gramática y vocabulario de la lengua mexicana. William Gates Collection en la Latin American Library de la Universidad de Tulane (Nueva Orleans) [Rare 497.2017051).

NTLE = Nuevo Tesoro Lexicográfico del Español (siglos XIV-1726). 2007. Dirs. L. Nieto Jiménez y M. Alvar Ezquerra. Madrid: Real Academia Española; Arco Libros.

Olmos, Andrés, fray. 1985. Arte de la lengua mexicana y vocabulario [c. 1547]. Eds. Thelma D. Sullivan y René Acuña. México D.F.: Universidad Nacional Autónoma de México.

Rivarola, José Luis. 2001. La lengua materna. Conciencia lingüística y conciencia retórica en el Inca Garcilaso. En El español de América en su historia. José Luis Rivarola, 159-80. Valladolid: Universidad de Valladolid.

Robles, Carlos. 1964. Problemas que se presentan en la expresión de los conceptos filosófico-religiosos del cristianismo en las lenguas indígenas de América. XXXV Congreso de Americanistas, México 1962. Actas y Memorias, 2: 615-34. México D.F.: Editorial Libros de México.

Ruiz de Montoya, Antonio. 1640. Arte y bocabvlario de la lengva gvarani. Madrid: Juan Sánchez.

Sahagún, Bernardino de, fray. 1979. Códice Florentino de Fray Bernardino de Sahagún [1578]. 3 tomos. Florencia: Imp. Talleres Casa Editorial Giunti Barberá. [Reproducción facsimilar del ejemplar que conserva la Biblioteca Medicea Laurenziana].

Sánchez Vázquez, Rafael. 2002. Síntesis sobre la Real y Pontifica Universidad de México. Anuario Mexicano de Historia del Derecho 14: 265-342.

Santo Tomás, Domingo de. 1951 [1560]. Lexicón, o vocabulario de la lengua general del Perú [1560]. Ed. Raúl Porras Barrenechea. Lima: Universidad Nacional Mayor de San Marcos, Instituto de Historia.

Schlenther, Ursula. 1968. Conceptos cristianos en textos indígenas de los siglos XVI al XX. Traducciones mesoamericanistas, 2: 221-46. México D.F.: Sociedad Mexicana de Antropología.

Smith-Stark, Thomas C. 2009. Lexicography in New Spain (1492-1611). Missionary linguistics IV/ Lingüistica misionera IV. Lexicography Selected papers from the Fifth International Conference on Missionary Linguistics, Mérida, Yucatán, 14-17 March 2007, eds. Otto Zwartjes, Ramón Arzápalo, y Thomas C. Smith-Stark, 3-82. Amsterdam; Filadelfia: John Benjamins.

Taboada Cid, Manuel. 1989. Lingüística renacentista: lenguas y dialectos en las gramáticas españolas de los siglos XVI, y XVII (1492-1630). Anuario Galego de Filoloxia 16: 77-95.

Todorov, Tzvetan. 2003. La conquista de América. El problema del otro. México D.F.: Siglo XXI.

Zimmermann, Klaus. 2004. La construcción del objeto de la historiografía lingüística misionera. En Missionary linguistics/ Lingüistica misionera. Selected papers from the First International Conference on Missionary Linguistics (Oslo, 13-16 March, 2003), eds. Otto Zwartjes y Even Hovdhaugen, 8-32. Amsterdam; Filadelfia: John Benjamins.

Zwartjes, Otto, Ramón Arzápalo Marín y Thomas C. Smith-Stark, eds. 2009. Missionary linguistics IV / Lingüistica misionera IV. Lexicography Selected papers from the Fifth International Conference on Missionary Linguistics, Mérida, Yucatán, 14-17 March 2007. Amsterdam; Filadelfia: John Benjamins. 